magma) is far more indicative of formation by water, and is not usual in pegmatites, so far as I know them; if, indeed, all these are igneous rocks. Mr. Lomas, however, may reply that he does not assert all quartz veins, oven if including felspar and mica, to be igneous, but only that at Foxdale. But if so, we may fairly ask him to tell us bow to distinguish igneous from aqueous veins. The former, when they cut through sedimentary rock, especially if it be argillaceous, generally produce rather conspicuous structural and mineral changes, so that here I expected Mr. Lomas to give a careful description of the contactmetamorphism or to offer an explanation of its absence. Instead of this I find only the vague phrase 'altered slate'-a phrase compatible with slight silicification or other changes such as may take place by ordinary infiltration, and thus be no help to his hypothesis. I do not deny that differentiation might possibly be carried so far in an ordinary acid magma as to leave a residuum of pure or nearly pure silica (though I have never met with an instance of it), but I think it more probable that, as Mr. Lomas substitutes at critical points vague phrases and inconsequent statements for precise description, he has yielded to the fascination of a novel bypothesis.

P.S.-The above was written before the publication of Mr. Harker's letter (p. 95).

T. G. BonneY.

THE ORIGIN OF QUARTZ-VEINS.

Sir,-In connection with the question of the origin of certain quartz-veins, ${ }^{1}$ the fact that quartz reveals plastic qualities at temperatures considerably below the melting-points of many undoubted igneous minerals must be born in mind. J. JoLY.

Trinity College, Deblin.

February $9 t h, 1903$.

NEW GEOLOGICAL TERMS AND FALSE ETYMOLOGY.

Sir,-As no one seems inclined to protest against the terms 'calcrete' and ' silcrete' with which Mr. Lamplugh proposes (in your December number ${ }^{2}$ ) to disfigure geological nomenclature, I must even raise a voice in the desert. Brief expressions for what he intends them to convey would doubtless be useful, and no one would be likely to quarrel with 'calcicrete' and 'silicicrete,' of which one would be two, the other three, letters longer. I adnit that public convenience may sometimes prevail over strict etymological rules, as in preferring the inaccurate 'telegram' to 'telegrapheme'; but 'calcrete' and 'silcrete' are even worse than the fashionable mongrel 'peneplain,' and approximate in malformation to the hideous 'phenocryst,' which seems invented to signalize the divorce of goology from culture.

T. G. Bonnky.

THE DEHYDRATION OF LATERITE.

SIR, - The very interesting paper on "The Constitution of Laterite," by Mr. T. H. Holland, appearing in your issue for February, 1903, raises several questions of chemical physics which

1 See Mr. J. Lomas's article, Geological Magazise, January Number, p. 34, and Mr. Alfred Harker's letter, February Number, p. 95.

2 Geol. Mag., December, 1902, p. $0 \bar{T}$. 
are of the utmost importance from a geological standpoint. That crystalline affinity is a definite molecular force accompanied by exothermic changes is doubtless correct, but whether this force can determine chemical changes of an endothermic character is a question involving an entirely new conception, and requires careful consideration before it can be accepted as a rersonable hypothesis. More especially is this the case when we have to deal with the constitution of hydrates, which afford such excellent examples of the application of the phase rule in chemical physics. Hydrates, as is well known, have a vapour pressure of their own, and only continue to exist when in equilibrium with the vapour pressure which they have to support. 'I'hus the hydrates of copper sulphate can be successively decomposed under varying conditions of temperature or pressure. The instability of the aluminium hydrate, $\mathrm{Al}_{2} \mathrm{O}_{3} \cdot 3 \mathrm{H}_{2} \mathrm{O}$, at moderate temperatures, also, is a fact well known in chemistry; and it seems probable that the occurrence of any hydrate, either of aluminium or of iron, in uature will depend upon which happens to be the stable phase under the existing conditions of temperature and pressure.

In connection with the crystallization of alumina the researches of W. Spring, of Liège, appear to have some bearing. According to this observer, amorphous alumina or ferric oxide, if dawp, can be rendered compact, presumably with the occurrence of an incipient crystallization, by pressure alune; and we are induced to consider whether the amorphous state in solids may not, in some cases at least, be comparable with the condition of superfused solutions and glasses. In fact, many of the distinctions between solids and liquids are gradually breaking down under the researches of modern physics.

There does not, therefore, appear to be any necessity for a new theory to explain the facts in this case. It appears rather that Mr. Holland has unnecessarily introduced a difficulty by presupposing that the molecules in laterite are isolated from extraneous energy. If this were really the case there could be no change of entropy such as he describes, and rightly, to be the result of the reactions involved.

J. Vincent Elsden.

38, St. Stephen's Gardens, Twickenham.

\section{THE COLOUR OF GLASLYN AND OF LLYN LLYDAW.}

Sir, - Glaslyn and Llydaw are the names of the two chief Snowdonian tarns. Glaslyn has been noted from time immemorial for the greenish colour of its water, as is implied by its name; but until the Summer of 1899 there was nothing peculiar about the colour of Llydaw. During that Summer, however, for the first time within the last fifty years at least, the water of Llyn Llydaw became as green as that of Glaslyn. The cause of this remarkable change of colour is not far to seek; for in the Spring of 1899 , some time about March I am told, the company that works the Snowdon Copper Mine commenced crushing and washing their ore on the bank of Llydaw, so that a large quantity of greenish débris was 